\title{
ANÁLISE COMPORTAMENTAL DO DIREITO: aplicação de sanções pelo Tribunal de Contas da União a gestores com contas irregulares //
}

Jorge M. Oliveira-Castro ${ }^{1}$, Adriana de Oliveira ${ }^{2}$, Julio C. de Aguiar ${ }^{3}$

\author{
Palavras-chave \\ análise comportamental do direito / prestação de \\ contas / aplicação de sanções / Tribunal de Contas \\ da União / Lei n ${ }^{\circ} 8.443 / 92$
}

HIIIIIIIIIIIIIIIIIIIIIIIIIIIIIIII

\section{Sumário}

\section{Introdução}

1.1 Análise Comportamental do Direito

1.2 Aplicações de Sanções pelo TCU

2 Método

3 Resultados

3.1 Análises Descritivas

3.2 Aplicações de Sanções pelo TCU

4 Discussão

5 Referências

\section{Resumo}

A análise comportamental do direito concebe o direito como um sistema cuja função social é reduzir a ocorrência de comportamentos definidos politicamente como socialmente indesejáveis (e.g., delitos), predominantemente mediante o uso de coerção. As normas jurídicas são formadas por padrões de comportamentos entrelaçados, emitidos por indivíduos em diferentes instituições, que são influenciados por aumentos (comportamento punitivo) ou diminuições (comportamento defensivo) na probabilidade de aplicação de sanções. O comportamento de aplicar sanções, tipicamente por um magistrado, desempenha função crucial na cadeia de comportamentos jurídicos, tendo em vista que ocorre no final da cadeia e retroalimenta todos os nós que o antecedem. Na presente pesquisa investigou-se a aplicação de sanções pelo Tribunal de Contas da União contingentes ao comportamento de gestores de recursos federais que tiveram suas contas julgadas irregulares. Para isso, foram examinadas as informações contidas em duas amostras aleatórias (371 nomes em cada), extraídas da lista pública de responsáveis com contas irregulares enviadas à justiça eleitoral. Os resultados indicaram que: a) a porcentagem média da multa do art. 57 da Lei 8.443/92, com relação ao valor do débito, foi de $16 \%$ nas duas amostras; b) os valores dessa multa aumentaram significativamente com aumentos no valor do débito e para condutas com indícios de má-fé dos gestores; e c) a porcentagem dessa multa diminuiu significativamente com aumentos no valor do débito. Tomados em conjunto, os resultados sugerem a utilidade do arcabouço teórico da análise comportamental do direito para a investigação empírica e a interpretação de comportamentos jurídicos.

1 PhD, Experimental Psychology, Auburn University, USA. Professor no Instituto de Psicologia da UnB. Auditor de Controle Externo no Tribunal de Contas da União.

2 Centro Universitário do Distrito Federal. Doutora em Ciências do Comportamento, Universidade de Brasília.

3 Doutor em Direito pela Universidade Federal de Santa Catarina e $\mathrm{PhD}$ in Law pela University of Aberdeen, UK. Professor da Graduação e do Mestrado em Direito da Universidade Católica de Brasília. 


\section{BEHAVIORAL ANALYSIS OF LAW: application of sanctions by the Federal Court of Accounts to managers with irregular accounts //}

Jorge M. Oliveira-Castro, Adriana de Oliveira e Julio C. de Aguiar

\section{Keywords}

behavioral analysis of law / account rendering / application of sanctions / Federal Court of Accounts / Law 8.443/92

HIIIIIIIIIIIIIIIIIIIIIIIIIIIIIIIII

\begin{abstract}
The behavioral analysis of law interprets law as a system whose social function is to reduce the occurrence of politically defined socially undesirable behavior (e.g., offenses), predominantly with the use of coercion. Legal norms are formed by interlocked behavioral patterns, emitted by individuals in different institutions, that are influenced by increases (punitive) or decreases (defensive) in the probability of sanctions being applied. The behavior of applying sanctions, typically by a judge, performs a crucial function in the legal behavior chain, considering that it occurs at the end of the chain and provides feedback to all its antecedent nodes. In the present research, the application of sanctions by the Federal Court of Accounts contingent to the behaviorof managers of federal resources who had their accounts judged as irregular. In order to do this, information contained in two random samples (371 names in each), drawn from the public list, sent to the electoral justice, that contains the names of people whose accounts were judged as irregular. Results indicated that: a) the mean percentage of the fine, established in article 57 of the Law 8.443/92, relatively to the liability value, was equal to $16 \%$ in the two samples; b) the value of this fine increased significantly with increases in the liability value and for offenses perpetrated in bad faith; and c) the percentage of this fine decreased significantly with increases in the liability value. In general, results suggest the utility of the theoretical framework advanced by the behavioral analysis of law for the empirical investigation and the interpretation of legal behavior.
\end{abstract}




\section{Introdução}

Como as leis influenciam o comportamento das pessoas? Essa tem sido uma questão central e recorrente na filosofia do direito (e.g., Kelsen, 1960/1998). Questiona-se, por exemplo, se coerção e a possibilidade de uso de força física são características essenciais para que a lei seja obedecida ou se as pessoas obedecem a lei simplesmente porque é a lei, independentemente das consequências punitivas (cf. Hart, 1994; Schauer, 2015).

Mesmo sem um aprofundamento na análise dessas questões, que não caberia no escopo do presente trabalho, é possível reconhecer que elas se caracterizam, pelo menos em parte, como questões empíricas, as quais não são passíveis de serem respondidas sem o uso de algum tipo de observação do comportamento das pessoas, de forma direta ou indireta (e.g., dados secundários) (cf. Harzem\& Miles, 1978). Esse tipo de informação, obtida por pesquisas empíricas, extrapola o âmbito típico da pesquisa jurídica, que geralmente fica circunscrita aos livros, onde se examinam os textos das leis, a jurisprudência e a doutrina.

O reconhecimento da importância de análises empíricas para a compreensão do sistema jurídico e de seu papel na sociedade tem sido crescente nos últimos anos (cf.Eisenberg, Rachlinski, Schwab\& Wells, 2004; Schauer, 2015) e tem contribuído para aproximar o direito de outras áreas de conhecimento, tais como economia (e.g., Posner, 2007/1973; Epstein, Landes \&Posner, 2012), antropologia (e.g., Lima \&Varella, 2008 e Lima, 2008), sociologia (e.g., Machado-Neto, 1987 e Scuro-Neto, 2009) e estatística (e.g., Nunes, 2012; Zabala\&Silveira, 2014). Tendo em vista que a maioria das questões empíricas, suscitadas pelo direito, estão relacionadas ao comportamento de indivíduos, a interação com a psicologia se torna particularmente promissora. Tal relação também tem sido crescente, principalmente com a subárea da psicologia conhecida como análise do comportamento, que conta com um sólido arcabouço metodológico-conceitual, desenvolvido ao longo do último século e fundamentado em volumoso conjunto de pesquisas experimentais e não experimentais, básicas e aplicadas, especialmente desenvolvido para identificar as variáveis que influenciam o comportamento dos indivíduos (e.g., Skinner, 1953, 1957; Todorov, 2004, 2005).
Nos últimos anos, esse arcabouço conceitual da análise do comportamento tem sido adotado por Aguiar para propor uma interpretação abrangente do sistema jurídico e de suas relações com a sociedade, compatível com uma teoria operante do comportamento (cf. Aguiar, 2012, 2013, 2014, 2015, 2016, 2017; Aguiar \&Gobbo, 2016). Exatamente por ser baseado em uma análise funcional operante do comportamento, o modelo proposto aponta para as possíveis variáveis influenciadoras do comportamento jurídico e, por isso, se mostra propício para fundamentar estudos empíricos do direito. No presente trabalho, esse arcabouço servirá de base para o exame da aplicação de sanções, pelo Tribunal de Contas da União, aos gestores de recursos públicos que tiveram suas prestações de contas julgadas irregulares.

\subsection{Análise Comportamental do Direito}

Baseado no conceito de sistema social funcionalmente especializado desenvolvido por Luhmann (Luhmann, Bednarz, \&Baecker, 1995), Aguiar (2017) concebe o direito como um sistema cuja função social é reduzir a ocorrência de comportamentos socialmente indesejáveis, predominantemente mediante o uso de coerção. Sistemas sociais funcionalmente especializados foram selecionados, ao longo da evolução da sociedade, como práticas de grupos de pessoas que aumentam a probabilidade de sobrevivência, reprodução e bem-estar do grupo. De acordo com Aguiar (2017), um dos principais componentes de sistemas sociais funcionalmente especializados é a norma social, interpretada como padrões de comportamentos do grupo que controlam os comportamentos de seus membros mediante a apresentação de consequências reforçadoras (i.e., que aumentam a probabilidade do comportamento que as produziu) e punitivas (i.e., que diminuem a probabilidade do comportamento que as produziu) (cf. Skinner, 1953). Por exemplo, uma norma que estabeleça que as pessoas devem ceder seu assento em lugares públicos, para pessoas idosas ou com necessidades especiais, constitui uma contingência programada de reforço social que institui consequências sociais punitivas (e.g., na forma de reclamação dos outros) para os indivíduos que não cederem seus assentos nas situações esperadas. Os padrões de comportamentos que constituem a norma são entrelaçados no sentido de se influenciarem reciprocamente, isto é, o com- 
portamento de não ceder o lugar é condição para a ocorrência do comportamento de reclamar. Trata-se de um estímulo discriminativo, isto é, que sinaliza o aumento na probabilidade de reforço, que no presente caso é reforço negativo (cf. Catania, 1999; Skinner, 1953), pois sinaliza que uma resposta de reclamação eliminará a situação aversiva de "não ceder o lugar". Por outro lado, o comportamento de reclamar é reforçado ou não a depender do comportamento do indivíduo que sentou no lugar indevido. Se a pessoa se retira contingentemente à reclamação, o reclamar é reforçado, se não se retira, o comportamento de reclamar está em extinção e tenderá a deixar de ocorrer com a repetição de casos semelhantes.

De acordo com essa interpretação, norma jurídica é uma espécie de norma social, que pode ser interpretada como padrões entrelaçados de comportamentos que são mantidos ou alterados em função do aumento ou diminuição na probabilidade de controle coercitivo de comportamentos sociais politicamente (e.g., com base em decisão legislativa) considerados indesejáveis. Os padrões de comportamentos entrelaçados incluem dois tipos de comportamentos jurídicos, quais sejam, punitivos e defensivos. Comportamentos jurídicos punitivos são aqueles influenciados por aumentos na probabilidade de aplicação ou na magnitude de sanções jurídicas (e.g., investigação policial, apresentação de denúncia por promotor), enquanto os defensivos se alteram em função de diminuições nessa probabilidade ou na magnitude da sanção (e.g., petição de advogado de defesa, proposta de delação premiada de um réu). Tais comportamentos entrelaçados formam uma rede de comportamentos jurídicos, emitidos por pessoas de diferentes instituições, tais como as polícias (e.g., civil, militar e federal), os advogados, procuradores, promotores, juízes e tribunais. Os nós dessa rede são formados por comportamentos que se influenciam reciprocamente, ao gerar reforço para comportamentos antecedentes (e.g., Ministério Público apresenta uma denúncia com base na investigação da polícia) e estímulos discriminativos para comportamentos subsequentes (e.g., a denúncia serve de base para uma decisão do juiz).

Dentre os comportamentos que compõem as normas jurídicas, comportamentos verbais de enunciação de regras jurídicas são típicos e relevantes para a manutenção e aprimoramento de tais normas (Aguiar, 2017). Comportamentos de enunciação de regras são reforçados pelas alterações que produzem no repertório de outros indivíduos. Por exemplo, quando uma advogada de defesa cita textos de leis em uma petição, ela está a enunciar regras jurídicas (e.g., 'Excelentíssimo Juiz da $1^{\text {a }}$ Vara Criminal da Comarca da Capital, o inciso II do art. 23 do Código Penal dispõe que "não há crime quando o agente pratica o ato em legítima defesa" [...]'). Tal comportamento é, ou não, reforçado pela redução na probabilidade de aplicação de uma sanção por parte de um juiz. 0 texto da lei funciona como estímulo discriminativo para a enunciação de regras, ou seja, funciona como um evento cuja presença sinaliza aumento na probabilidade de reforço para enunciação de uma determinada regra, por exemplo, na diminuição da probabilidade ou magnitude da sanção que pode ser aplicada ao seu cliente. Isso porque, ao citar a lei, a enunciação de regra sinaliza (estímulo discriminativo) ao juiz, ou outro membro da rede, um possível aumento na probabilidade de ocorrerem consequências aversivas, tais como críticas, desaprovação (e.g., colegas magistrados, juristas, mídia, ou até corregedorias) ou reversão de decisão por instâncias superiores (e.g., Epstein et al., 2012), tendo em vista que o texto da lei registra uma decisão política que autoriza, ou não, o uso de coerção no tipo de situação envolvida no caso. Nas sociedades modernas, tipicamente, o uso de coerção, mesmo para autoridades, só pode ocorrer se estiver autorizado por uma decisão política, registrada em lei que representa, teoricamente, uma decisão da maioria da sociedade. Caso o texto da lei não possa servir de estímulo discriminativo para a aplicação de determinada sanção (e.g., não tem funcionado assim tipicamente, o que pode ser constatado com base em consulta à jurisprudência), não houve uma decisão política (legislativa) que tenha autorizado a aplicação da referida sanção naquele tipo de situação. Para Aguiar, as consultas aos textos da lei tipicamente ocorrem em situações de resolução de problemas (e.g., processo entregue ao juiz para emissão de sentença) e funcionam como comportamentos precorrentes que aumentam a probabilidade de reforço para a resposta final (cf. Oliveira-Castro, Coelho \& Oliveira-Castro, 1999; Polson\&Parsons, 1994; Skinner, 1968, 1969), por exemplo, para o comportamento de proferir a sentença. 
Aguiar (2017) propôs um modelo para possibilitar análise funcional de regras jurídicas de acordo com o qual essas regras são formadas pelos seguintes elementos: premissas factuais relevantes, que são as relações causais que ligam a instituição da contingência coercitiva entre delito e sanção à obtenção do estado de coisas socialmente desejável, baseadas em conhecimento proveniente das ciências; meta social, que é o estado de coisas politicamente definido como desejável, no sentido da sobrevivência, reprodução e bem-estar da sociedade, a qual pode ser imediata, redução do comportamento socialmente indesejável, ou mediata, algo que ocorreria como consequência do comportamento punido (e.g., preservação de mananciais hídricos pode ser alcançada, em parte, com a punição de comportamentos que geram danos a tais mananciais); e contingência jurídica, que é a contingência coercitiva entre delito e sanção, a qual especifica as condutas socialmente indesejadas e as sanções a serem aplicadas. De acordo com a proposta, essa fórmula desenvolvida para analisar regras jurídicas fornece uma base teórica para grande parte do trabalho de juristas, cuja tarefa incluiria a explicitação desses elementos das leis, a qual, por sua vez, auxiliaria a prática dos operadores do direito.

Esse arcabouço teórico da análise comportamental do direito serve de fundamento para uma ampla gama de pesquisas empíricas sobre as variáveis que podem influenciar as relações entre normas jurídicas e o comportamento dos destinatários e operadores do direito.Dentre as investigações empíricas de interesse, a análise das relações entre as regras enunciadas por magistrados, por exemplo ao proferirem sentenças, e os estímulos discriminativos presentes na situação, tais como elementos do texto da lei e dos casos específicos julgados, se sobressai devido ao papel crucial que essas relações funcionais desempenham na manutenção e funcionamento de toda a rede comportamental jurídica. Isso porque o comportamento do magistrado de proferir sentença, tipicamente, forma o nó final de uma longa cadeia de comportamentos de vários atores e, por isso, tem a função de reforçar, ou não, grande parte dos comportamentos jurídicos, punitivos e defensivos, antecedentes. Se o magistrado nunca (ou sempre) aplica uma determinada sanção para certo tipo de conduta, emitida em um determinado tipo de contexto, toda a cadeia de comportamentos jurídicos punitivos (ou defensivos) antecedentes deixará de ocorrer, pois não haverá mudança na probabilidade de reforço para tais comportamentos. Por exemplo, se magistrados (ou tribunal) nunca condenam um certo delito tributário quando este ocorreu há mais de cinco anos (i.e., por considerar que houve prescrição, independentemente de haver lei estabelecendo isso), comportamentos jurídicos punitivos de procuradores e fiscais da receita, por exemplo, tenderão a deixar de ocorrer quando o tempo desde o delito se aproximar dos cinco anos. Portanto, toda a cadeia de comportamentos jurídicos entrelaçados depende, em última instância, da probabilidade de aplicação de sanções pelos magistrados (antes ou após as instâncias recursais cabíveis).

\subsection{Aplicação de sanções pelo TCU}

No presente trabalho esse tipo de exame foi realizado com respeito à aplicação de sanções pelo Tribunal de Contas da União contingentes ao comportamento de gestores de recursos públicos federais. 0 Tribunal de Contas da União (TCU), órgão federal de controle externo da administração pública, funciona como um tribunal administrativo. É um órgão colegiado, cujas deliberações ocorrem no Plenário (instância máxima que reúne todos os ministros), na Primeira Câmara e na Segunda Câmara (colegiados nos quais os ministros se dividem).

As competências do Tribunal de Contas da União estão descritas nos art. 70 e 71 da Constituição Federal, c/c o art. $1^{\circ}$ da Lei $n^{\circ}$. 8.443, de 16.07.1992 (Lei Orgânica do Tribunal de Contas da União). Dentre essas diversas competências, o TCU julga as contas dos ordenadores de despesa e demais responsáveis por dinheiros, bens e valores públicos da administração direta e indireta e as contas daqueles que derem causa a perda, extravio ou outra irregularidade de que resulte prejuízo ao erário. Outra competência trata da fiscalização da aplicação de quaisquer recursos repassados pela União mediante convênio, acordo, ajuste ou outros instrumentos congêneres, ao Estado, ao Distrito Federal ou aos Município. A regra do inciso VI do art. 71 da Constituição Federal exige a comprovação por parte dos Estados, Municípios e Distrito Federal dos gastos e da maneira como foram utilizados os recursos públicos federais recebidos mediante convênios ou contratos. Para exercer tais 
competências, o texto constitucional (art. 71, inciso VIII) autoriza o TCU a "aplicar aos responsáveis, em caso de ilegalidade de despesa ou irregularidade de contas, as sanções previstas em lei, que estabelecerá, entre outras cominações, multa proporcional ao dano causado ao erário".

Uma das competências do TCU, que tem especial interesse para o presente trabalho, é o julgamento dos processos de Tomada de Contas Especial (TCE), relacionada a recursos públicos federais. A tomada de contas especial tem por objetivo apurar os fatos, identificar os responsáveis e quantificar o dano, para obter o devido ressarcimento, quando houver indícios de irregularidades que podem ter causado prejuízo aos cofres públicos (cf. art. $8^{\circ}$ da Lei 8.443/92; art. 197 do Regimento Interno do TCU, RITCU, de 2015). A má conduta do gestor pode se dar pela omissão no dever de prestar contas, pelas irregularidades na gestão do recurso público causando dano ao erário, pela não execução ou execução parcial do objeto para o qual o dinheiro foi destinado. Pode ainda ser causada pelo desvio de finalidade para a qual o recurso foi destinado, ocorrência de desfalque, desvio ou desaparecimento do dinheiro, bens ou valores públicos, dentre outras irregularidades.

As TCE somente são instauradas depois que todas as medidas administrativas foram adotadas para tentar reaver os recursos dentro do órgão ou entidade no qual ocorreu o dano. Uma vez que todas as medidas possíveis sejam esgotadas dentro do órgão ou entidade, a TCE deve ser instaurada imediatamente. Quando a TCE é instaurada no órgão ou entidade, esta tem 45 dias para ser enviada ao Ministério da Transparência, Fiscalização e Controladoria-Geral da União (CGU) e este tem até 180 dias para enviar o processo para o TCU, onde ele será julgado.As TCE podem também ser instauradas diretamente pela CGU ou TCU, quando verificada irregularidade no âmbito de suas fiscalizações. A decisão definitiva do TCU é expressa via acórdão, que é publicado no Diário Oficial da União. As prestações e tomadas de contas podem ser julgadas como regulares (art. 16, inciso I, da Lei 8.443/92; art. 207 do RITCU/2015), como regulares com ressalva (art. 16, inciso II, da Lei 8.443/92; art. 208 do RITCU/2015) ou como irregulares (art. 16, inciso III, da Lei 8.443/92; art. 209 do RITCU/2015).
As contas serão julgadas irregulares quando comprovada qualquer das seguintes ocorrências (art. 16, inciso III, da Lei 8.443/92): a) omissão no dever de prestar contas;b) prática de ato de gestão ilegal, ilegítimo, antieconômico, ou infração à norma legal ou regulamentar de natureza contábil, financeira, orçamentária, operacional ou patrimonial;c) dano ao Erário decorrente de ato de gestão ilegítimo ao antieconômico;d) desfalque ou desvio de dinheiros, bens ou valores públicos.

O art. 19 da Lei 8.443/92 estabelece que, quando julgar as contas irregulares: a) havendo débito (i.e., dano ao erário quantificado), o Tribunal condenará o responsável ao pagamento da dívida atualizada monetariamente, acrescida dos juros de mora devidos, podendo, ainda, aplicar-lhe a multa prevista no art. 57 desta Lei, sendo o instrumento da decisão considerado título executivo para fundamentar a respectiva ação de execução; e b) não havendo débito, mas comprovada qualquer das ocorrências previstas nas alíneas a, b e c do inciso III, do art. 16, o Tribunal aplicará ao responsável a multa prevista no inciso I do art. 58, desta Lei. Quanto ao valor das multas, o art. 57 , acima mencionado, estabelece que quando o responsável for julgado em débito, poderá ainda o Tribunal aplicar-lhe multa de até cem por cento do valor atualizado do dano causado ao erário, enquanto o art. 58 especifica multa, cujo valor máximo é periodicamente atualizado pelo TCU (valor para 2017 igual a R\$58.269,07). Além do débito e das multas, o TCU poderá ainda aplicar a sanção de inabilitação para exercer cargo em comissão ou função de confiança no âmbito da administração pública federal, por um período que variará de cinco a oito anos, sempre que, por maioria absoluta de seus membros, considerar grave a infração cometida (art. 60 da Lei 8.443/92 c/c art. 270 do RITCU/2015). Portanto, essas são as principais sanções aplicáveis pelo TCU no caso de julgamento de contas irregulares, as quais compõem as contingências jurídicas de punir comportamentos relacionados ao uso inadequado de recursos públicos, associadas à meta imediata de reduzir tais comportamentos indesejáveis, com base na premissa de que, ao reduzir tais comportamentos, os recursos serão melhor geridos, o que possibilitaria o alcance de metas mediadas, afetas a outros sistemas sociais, tais como oferecer à população serviços de qualida- 
de nas áreas de educação, saúde, segurança, transporte, dentre várias outras.

O principal objetivo da presente pesquisa foi analisar o controle discriminativo que esses textos legais e outros elementos dos casos específicos (e.g., valor do dano causado) exercem sobre o comportamento dos ministros do TCU na aplicação de sanções em processos nos quais as contas foram julgadas irregulares. Para tal, descreveram-se algumas características dos processos de contas julgadas irregulares, tais como duração do processo, valores dos débitos, valores médios das multas, cargo ou função dos responsáveis, tipo de conduta irregular, dentre outras, bem como exploraram-se relações preditivas entre algumas dessas variáveis e os valores das multas aplicadas.

\section{Método}

O Tribunal de Contas da União gera uma lista com a relação de responsáveis com contas julgadas irregulares durante os oito anos que precedem cada eleição. Essa lista é encaminhada ao Tribunal Superior Eleitoral (TSE) a cada dois anos com base na Lei 9.504/1997 (Lei Eleitoral) e na Lei Complementar 135/2010 (Lei da Ficha Limpa), para que o TSE avalie e determine quais pessoas se tornarão inelegíveis. As informações são públicas e acessíveis através do site do TCU. No presente trabalho, utilizou-se a lista remetida ao TSE em 2014 com 10.512 nomes de responsáveis, pessoas físicas, que tiveram suas contas julgadas irregulares.

Essa lista possui um link para o site do TCU com acesso aos acórdãos associados aos processos. Os acórdãos contêm as decisões relativas aos processos de TCE proferidas pelo Plenário ou pela $1^{\mathrm{a}}$ ou $2^{\mathrm{a}}$ Câmaras. Eventualmente, o processo de TCE pode ter só um acórdão, mas isso nem sempre ocorre, por haver recursos ou diferenças nos votos dos ministros. Em cada um dos processo examinados, foram identificadas as seguintes informações: valor do débito (valor do dano ao erário que precisa ser ressarcido), valor da multa com a fundamentação legal de sua aplicação (art. 57 e/ou 58 da Lei 8.443/92), o órgão que instaurou a TCE, os cargos dos responsáveis na TCE, se houve recurso quanto a alguma decisão do TCU, se os processos envolviam convênios, a duração do processo, se a sanção de inabilitação para o exercício de função pública foi aplicada, motivo de instauração baseado no art. 16, inciso III, alíneas "a", "b", "c" e "d" da Lei 8.443/92, e mesmo se ocorreu combinações entre as alíneas (e.g., "ab”, "acd”, "abcd” etc).

Quando alguma informação não era identificada no acórdão, isso foi rotulado como missing (dado ausente). Alguns processos estavam classificados como sigilosos, nesses casos, o acesso à maioria das informações era restrito e foram classificadas as informações disponíveis e consideradas como missing as demais.

Como variáveis dependentes, foram selecionadas as possíveis sanções aplicadas pelo TCU quando as contas são julgadas irregulares, a saber:

1. Valor da multa aplicada com base no art. $57 \mathrm{da}$ Lei 8.443, a qual pode ser aplicada ao responsável quando for julgado em débito. Nesse caso, a lei especifica que o Tribunal de Contas pode aplicar uma multa de até cem por cento do valor atualizado do dano causado ao erário;

2. Porcentagem do valor da multa prevista no art. 57 com relação ao valor do débito identificado no processo (e.g.,porcentagem sobre o montante do débito);

3. Multa do art. 58 da Lei $n^{\circ} 8.443$, que pode ser aplicada aos responsáveis quando suas contas forem julgadas irregulares, porém que não tenham resultado em dano ao erário, ou seja, sem valor de débito. Essa multa pode variar, de acordo com o art. 268 do RITCU/2015, a de 5\% a 100\% (5\% a 95\% no RITCU que estava em vigor na época em que os dados foram gerados) de um valor anualmente definido pelo Tribunal de Contas da União;

4. Sanção de inabilitação do art. 60 da Lei $n^{\circ} 8443$, que prevê que sem prejuízo das sanções descritas anteriormente e, se por maioria absoluta de seus membros, considerar grave a infração cometida, o responsável ficará inabilitado, por um período que variará de cinco a oito anos, para o exercício de cargo em comissão ou função de confiança no âmbito da Administração Pública.

Foram selecionadas duas amostras aleatórias e representativas (371 nomes em cada amostra) da planilha de 10.572 condenados pelo TCU no julgamento de 
contas irregulares. Na seleção da segunda amostra, quando era sorteado um número de processo constante da primeira amostra, foi selecionado o processo subsequente. Se este também estivesse na Amostra 1 , então foi selecionado o antecedente. Estimou-se um nível de confiança de 95\% e erro amostral de 5\%. As duas amostras aleatórias foram analisadas nos mesmos termos para garantir a fidedignidade. Para tanto, foi feito um cálculo conforme a fórmula abaixo:

$$
n=\frac{N \cdot Z^{2} \cdot p \cdot(1-p)}{Z^{2} \cdot p \cdot(1-p)+e^{2} \cdot(N-1)}
$$

Onde: $\mathrm{n}$ - amostra calculada; N - população; Z - variável normal padronizada associada ao nível de confiança; $p$ - verdadeira probabilidade do evento; e - erro amostral.

A análise dos dados foi dividida em duas etapas, sendo que a primeira apresenta estatísticas descritivas das variáveis, enquanto a segunda explora relações entre as variáveis.

\section{Resultados}

Os dados foram analisados utilizando o software IBM SPSS (20) e, conforme mencionado, as análises foram realizadas em duas partes: (1) análises descritivas para se identificar as características gerais dos processos, como duração do processo, número de responsáveis, montantes analisados e débitos, atos irregulares cometidos, quantidade de recursos, cargo do responsável, valores das multas, porcentagem das multas, estado da federação, instauração do processo, convênios, sigilo e sanção de inabilitação e (2) análises de regressão linear para identificar potenciais variáveis preditoras das sanções aplicadas pelo Tribunal de Contas da União (multa - art. 57 e 58, porcentagem da multa do art. 57 e sanção de inabilitação). Algumas variáveis só puderam ser analisadas como variáveis binárias (e.g., Processo Instaurado pelo TCU - Sim ou Não).

\subsection{Análises Descritivas}

A Tabela 1 apresenta a frequência absoluta e a porcentagem referente às condutas, que justificaram a instauração do processo de TCE, nas Amostras 1 e 2. As condutas foram classificadas com base no que estabelece o art. 16, inciso III, alínea "a", "b", "c" ou “d”, da Lei 8.443/92, ou combinação de tais condutas, quando mais de uma foi constatada no processo.

Tabela 1. Frequência absoluta e porcentagem referentes às condutas ilícitas sancionadas nos processos de TCE nas Amostra 1 e 2.

\begin{tabular}{|c|c|c|c|c|}
\hline \multirow[b]{2}{*}{ Condutas ilícitas } & \multicolumn{2}{|c|}{ Amostra 1} & \multicolumn{2}{|c|}{ Amostra 2} \\
\hline & Freq. & Porc. & Freq. & Porc. \\
\hline $\begin{array}{l}\text { Omissão no dever de } \\
\text { prestar contas (alínea } \\
\text { "a") }\end{array}$ & 44 & 11,9 & 42 & 11,3 \\
\hline $\begin{array}{l}\text { Prática de ato de gestão } \\
\text { ilegal, ilegítimo, antie- } \\
\text { conômico, ou infração } \\
\text { à norma legal ou regu- } \\
\text { lamentar de natureza } \\
\text { contábil, financeira, } \\
\text { orçamentária, opera- } \\
\text { cional ou patrimonial } \\
\text { (alínea "b") }\end{array}$ & 58 & 15,6 & 74 & 19,9 \\
\hline $\begin{array}{l}\text { Dano ao erário decorren- } \\
\text { te de ato de gestão ilegí- } \\
\text { timo ao antieconômico } \\
\text { (alínea "c") }\end{array}$ & 106 & 28,6 & 94 & 25,3 \\
\hline $\begin{array}{l}\text { Desfalque ou desvio de } \\
\text { dinheiros, bens ou valo- } \\
\text { res públicos (alínea "d") }\end{array}$ & 49 & 13,2 & 36 & 9,7 \\
\hline $\begin{array}{l}\text { Omissão no dever de } \\
\text { prestar contas e Prática } \\
\text { de ato de gestão ilegal } \\
\text { (alínea "a" e "b") }\end{array}$ & 0 & 0 & 6 & 1,6 \\
\hline $\begin{array}{l}\text { Omissão no dever de } \\
\text { prestar contas e dano ao } \\
\text { erário } \\
\text { (alínea "a" e "c") }\end{array}$ & 15 & 4,0 & 17 & 4,6 \\
\hline $\begin{array}{l}\text { Omissão no dever de } \\
\text { prestar contas e Desfal- } \\
\text { que ou desvio de dinhei- } \\
\text { ro (alínea "a" e "d") }\end{array}$ & 1 & 0,3 & 5 & 1,3 \\
\hline $\begin{array}{l}\text { Prática de ato de gestão } \\
\text { ilegal e Dano ao erário } \\
\text { (alínea "b" e "c") }\end{array}$ & 51 & 14,0 & 53 & 14,3 \\
\hline $\begin{array}{l}\text { Prática de ato de gestão } \\
\text { ilegal e Desfalque ou } \\
\text { desvio de dinheiro (alí- } \\
\text { nea "b" e "d") }\end{array}$ & 11 & 3,0 & 15 & 4,0 \\
\hline $\begin{array}{l}\text { Dano ao erário e Desfal- } \\
\text { que ou desvio (alínea "c" } \\
\text { e "d") }\end{array}$ & 12 & 3,2 & 13 & 3,5 \\
\hline Mais de dois atos ilícitos & 9 & 2,7 & 10 & 2,7 \\
\hline Missing & 8 & 2,2 & 6 & 1,6 \\
\hline Total & 371 & 100 & 371 & 100 \\
\hline
\end{tabular}


Pode-se observar na tabela que, para ambas as amostras, a conduta com maior frequência de ocorrência foi aquela descrita na alínea "c" (dano ao erário decorrente de ato de gestão ilegítimo ao antieconômico) que foi registrada em mais de $25 \%$ dos processos, seguida daquela mencionada na alínea "b" (prática de ato de gestão ilegal), com mais de $15 \%$ dos casos. A combinação das condutas "b" e "c" ocorreu em aproximadamente $14 \%$ dos casos, sendo a terceira mais frequente, seguida das condutas "a" (omissão no dever de prestar contas) e "d" (desfalques ou desvios de recursos) que estiverem presentes em aproximadamente $11 \%(9,7 \%$ a $13,2 \%)$ dos processos. As demais combinações de condutas ocorreram em menos de $5 \%$ dos casos cada uma.

Os dados indicaram ainda que: a quase totalidade das TCE não foram instauradas pelo TCU (Amostra 1 = 92,2\%, Amostra 2 =94,3\%); a maior parte das TCE inclui a situação de débito solidário, quando duas ou mais pessoas são solidariamente responsabilizadas pelo dano ao erário (Amostra $1=71,4 \%$; Amostra $2=$ $70,6 \%$ ) e que a maioria das TCE ocorreu na gestão de convênios (Amostra 1 = 59,0\%; Amostra 2 =65,0\%).

Na Tabela 2 foram descritos os cargos ou funções dos responsáveis das TCE em suas frequências absolutas e porcentagem. Os cargos que apareceram com $0,3 \%$ foram agrupados na categoria "outros". Das 10 categorias descritas, "Prefeito" é o cargo com a maior porcentagem nas TCE, $44,7 \%$ e $41,2 \%$ respectivamente das amostras analisadas.

Tabela 2. Frequência absoluta e porcentagem de ocorrência de cargo ou função do responsável das TCE nas Amostras 1 e 2.

\begin{tabular}{|l|l|l|l|l|}
\hline & \multicolumn{2}{|l|}{ Amostra 1 } & \multicolumn{2}{l|}{ Amostra 2 } \\
\hline & $\begin{array}{l}\text { Fre- } \\
\text { qu- } \\
\text { Cargo ou Função do } \\
\text { responsável } \\
\text { Abso- } \\
\text { luta }\end{array}$ & $\begin{array}{l}\text { Porcen- } \\
\text { tagem } \\
(\%)\end{array}$ & $\begin{array}{l}\text { Frequ- } \\
\text { ência } \\
\text { Abso- } \\
\text { luta }\end{array}$ & $\begin{array}{l}\text { Porcen- } \\
\text { tagem } \\
(\%)\end{array}$ \\
\hline Prefeito & 166 & 44,7 & 153 & 41,2 \\
\hline $\begin{array}{l}\text { Presidente ou Di- } \\
\text { retor }\end{array}$ & 39 & 10,5 & 47 & 12,7 \\
\hline $\begin{array}{l}\text { Gerente, Chefe ou } \\
\text { Coordenador }\end{array}$ & 23 & 6,2 & 34 & 9,2 \\
\hline
\end{tabular}

\begin{tabular}{|l|l|l|l|l|}
\hline Servidor & 25 & 6,7 & 13 & 3,5 \\
\hline $\begin{array}{l}\text { Membro da Comis- } \\
\text { são de Licitação ou } \\
\text { Fiscalização }\end{array}$ & 12 & 3,2 & 20 & 5,4 \\
\hline $\begin{array}{l}\text { Secretário Municipal } \\
\text { Bolsista CNPQ ou } \\
\text { CAPES }\end{array}$ & 7 & 3,8 & 9 & 2,4 \\
\hline Funcionário & 7 & 1,9 & 8 & 2,2 \\
\hline Secretário Estadual & 5 & 1,3 & 6 & 1,6 \\
\hline $\begin{array}{l}\text { Tesoureiro ou Con- } \\
\text { tador }\end{array}$ & 7 & 1,9 & 4 & 1,1 \\
\hline $\begin{array}{l}\text { Beneficiário de } \\
\text { Fraude }\end{array}$ & 1 &, 3 & 0 & 0 \\
\hline Outros & 13 & 3,5 & 16 & 4,3 \\
\hline Missing & 52 & 14,0 & 49 & 13,2 \\
\hline Total & 371 & 100 & 371 & 100 \\
\hline
\end{tabular}

A quantidade de processos de tomada de contas especial por unidade federativa foi analisada e descrita na Tabela 3 (frequência absoluta e porcentagem). As maiores incidências de processos ocorreram nos estados do Maranhão, seguidas por São Paulo, Minas Gerais, Rio de Janeiro e Paraná.

Tabela 3. Frequência absoluta e porcentagem das TCE por unidade federativa nas Amostras 1 e 2.

\begin{tabular}{|l|l|l|l|l|}
\hline & \multicolumn{2}{|l|}{$1^{\circ}$ Amostra } & \multicolumn{2}{l|}{$2^{\circ}$ Amostra } \\
\hline Estado do Processo & $\begin{array}{l}\text { Frequ- } \\
\text { ência } \\
\text { Abso- } \\
\text { luta }\end{array}$ & $\begin{array}{l}\text { Porcen- } \\
\text { tagem } \\
(\%)\end{array}$ & $\begin{array}{l}\text { Frequ- } \\
\text { ência } \\
\text { Abso- } \\
\text { luta }\end{array}$ & $\begin{array}{l}\text { Por- } \\
\text { cen- } \\
\text { ta- } \\
\text { gem } \\
(\%)\end{array}$ \\
\hline Acre (AC) & 5 & 1,3 & 6 & 1,6 \\
\hline Alagoas (AL) & 12 & 3,2 & 7 & 1,9 \\
\hline Amazonas (AM) & 19 & 5,1 & 12 & 3,2 \\
\hline Amapá (AP) & 8 & 2,2 & 9 & 2,4 \\
\hline Bahia (BA) & 18 & 4,9 & 22 & 5,9 \\
\hline Ceará (CE) & 13 & 3,5 & 13 & 3,5 \\
\hline $\begin{array}{l}\text { Distrito Federal } \\
\text { (DF) }\end{array}$ & 12 & 3,2 & 15 & 4,0 \\
\hline Espírito Santo (ES) & 7 & 1,9 & 11 & 3,0 \\
\hline
\end{tabular}




\begin{tabular}{|l|l|l|l|l|}
\hline Goiás (GO) & 6 & 1,6 & 9 & 2,4 \\
\hline Maranhão (MA) & 44 & 11,9 & 42 & 11,3 \\
\hline Minas Gerais (MG) & 23 & 6,2 & 24 & 6,5 \\
\hline $\begin{array}{l}\text { Mato Grosso do Sul } \\
\text { (MS) }\end{array}$ & 8 & 2,2 & 16 & 4,3 \\
\hline Mato Grosso (MT) & 13 & 3,5 & 10 & 2,7 \\
\hline Pará (PA) & 21 & 5,7 & 18 & 4,9 \\
\hline Paraíba (PB) & 14 & 3,8 & 9 & 2,4 \\
\hline Pernambuco (PE) & 20 & 5,4 & 21 & 5,7 \\
\hline Piauí (PI) & 6 & 1,6 & 10 & 2,7 \\
\hline Paraná (PR) & 21 & 5,7 & 19 & 5,1 \\
\hline Rio de janeiro (RJ) & 21 & 5,7 & 26 & 7,0 \\
\hline $\begin{array}{l}\text { Rio Grande do } \\
\text { Norte (RN) }\end{array}$ & 11 & 3,0 & 7 & 1,9 \\
\hline Rondônia (RO) & 7 & 1,9 & 8 & 2,2 \\
\hline Roraima (RR) & 3 &, 8 & 8 & 2,2 \\
\hline $\begin{array}{l}\text { Rio Grande do Sul } \\
\text { (RS) }\end{array}$ & 5 & 1,3 & 4 & 1,1 \\
\hline Santa Catarina (SC) & 8 & 2,2 & 6 & 1,6 \\
\hline Sergipe (SE) & 4 & 1,1 & 6 & 1,6 \\
\hline São Paulo (SP) & 31 & 8,4 & 24 & 6,5 \\
\hline Tocantins (TO) & 9 & 2,4 & 8 & 2,2 \\
\hline Missing & 21,5 & 100 \\
\hline Total & 371 & 371 \\
\hline
\end{tabular}

multa referente ao art. 57 pode chegar até a $100 \%$ do valor do débito e a multa do art. 58 varia de $5 \%$ a $100 \%$ de um valor anualmente definido pelo TCU. A média da porcentagem da multa referente ao art. 57 , calculada com relação ao valor do débito, foi de $16,8 \%$ (desvio-padrão igual a $16,6, \mathrm{~N}=287$ ) e $15,9 \%$ (desvio-padrão de 13,4\%, $N=267$ ) nas Amostras $1 \mathrm{e}$ 2 , respectivamente. No que se refere à multa prevista pelo art. 58, as porcentagens, calculadas com relação ao valor máximo definido pelo TCU no ano em que o processo foi finalizado, foram iguais a $13,4 \%$ (desvio-padrão de 13,1\%, N = 55) e 13,6\% (desvio-padrão de $13,1 \%, N=70$ ) nas Amostras 1 e 2, respectivamente.

Analisou-se também a aplicação da sanção prevista no art. 60 da Lei 8.443/92 que prevê a inabilitação para exercício de cargo em comissão ou função de confiança no âmbito da administração pública federal por um período que pode variar de 5 a 8 anos. De todas as sanções analisadas, essa foi a que ocorreu com menor frequência, tendo sido aplicada em 25 e 24 processos nas Amostras 1 e 2 , respectivamente. Por isso não foram realizadas análises preditivas envolvendo essa sanção. Uma das análises descritivas afeta à sanção do art. 60 foi verificar possíveis relações entre sua aplicação e o tipo de ilícito cometido. Na Amostra 1 constatou-se que $80 \%$ dos casos envolveram desfalque ou desvio, sendo $52 \%$ associados à alínea "d" e $28 \%$ à alínea "d" combinada com outra alínea. A mesma tendência foi observada na Amostra 2.

\subsection{Análises preditivas}

Com o objetivo de examinar possíveis variáveis preditoras dos valores das sanções aplicadas, foram realizadas regressões lineares múltiplas, considerando as seguintes variáveis quantitativas contínuas como dependentes, em diferentes análises: (1) valor da multa do art. 57, (2) porcentagem da multa do art. 57 e (3) valor da multa art. 58. Regressões múltiplas examinaram possíveis relações lineares entre essas variáveis dependentes como função das seguintes variáveis preditoras (ou independentes): montante do débito (contínua), montante analisado no processo (contínua), se houve recurso (categórica dicotômica), se tratava-se de convênio (categórica dicotômica), se houve débito solidário (categórica dicotômica).

Outro dado analisado foi a porcentagem das multas dos artigos 57 e 58. De acordo com a Lei 8.443/92, a

As variáveis independentes categóricas com mais de 
dois níveis, tais como cargos (prefeitos e secretários, presidentes e diretores e outros cargos) e conduta ilícita sancionada (com base no art. 16, inciso III, alínea "a", alínea "b", alínea "c", alínea "d" e "mais de um ato") foram transformadas em variáveis dummy. Para todas as análises, foi utilizado um critério de confiança de $95 \%$, ou seja, $p<0,05$.

As análises de regressão foram realizadas em três etapas. Primeiramente foram incluídas como preditoras todas as variáveis contínuas. As que foram significantemente relacionadas à variável dependente foram mantidas para a segunda etapa. Na segunda etapa, foram incluídas as variáveis dummy relacionadas ao cargo ocupado pelo responsável, sendo mantidas para a etapa seguintes apenas as que se mostraram significativamente relacionadas à variável dependente. Na terceira etapa, incluíram-se as dummy relacionadas ao tipo de conduta ilícita sancionada nos processos. Essas etapas foram realizadas para cada uma das variáveis dependentes examinadas.

A Tabela 4 apresenta o resultado final, depois das três etapas, das regressões com a variável dependente multa do art. 57 para a Amostra 1. Pode-se observar que a regressão incluiu como variáveis independentes apenas o "montante do débito" (primeira etapa) e os tipos de condutas sancionadas (terceira etapa). As variáveis incluídas na regressão explicaram 39,8\% $(R 2=0,398)$ da variabilidade no valor da multa do art. 57. Os parâmetros indicam que um aumento de R\$ 1,00 no montante do débito esteve associado a um aumento, estatisticamente significante, de $R \$ 0,11$ no valor da multa. Além disso, os resultados mostraram um aumento significante no valor da multa para os casos em que a conduta sancionada foi aquela prevista na alínea "d", ou seja, desfalque ou desvio de recursos, quando comparada às condutas de omissão no dever de prestar contas (alínea "a"), gestão ilegítima ou antieconômica (alínea "b"), e mais de um ato (combinações de mais de uma alínea). Quando comparada com a conduta de gestão ilegítima que causou dano ao erário (alínea "c"), a multa do art. 57 também foi maior para o caso de desfalque ou desvio (alínea "d"), sendo que a diferença esteve próxima do nível de significância estipulado $(p=0,05)$.
Tabela 4. Parâmetros da regressão linear da multa do art. 57 em função do montante do débito e do tipo de conduta sancionada para a Amostra 1.

\begin{tabular}{|l|l|l|l|l|}
\hline Amostra 1 & B & Erro Padrão & Beta & Sig. \\
\hline (Constant) & $-7979,65$ & 8429,79 & & 0,34 \\
\hline $\begin{array}{l}\text { Montante } \\
\text { do Débito }\end{array}$ & 0,11 & 0,01 & 0,62 & 0,00 \\
\hline Alínea "a" & $-13708,21$ & 15293,89 & $-0,04$ & 0,37 \\
\hline Alínea "b" & $-3279,39$ & 14011,75 & $-0,01$ & 0,82 \\
\hline Alínea "c" & 5075,62 & 11745,61 & 0,02 & 0,67 \\
\hline Alínea "d" & 33592,59 & 14724,74 & 0,11 & 0,02 \\
\hline (Constant) & $-21687,86$ & 12982,01 & & 0,09 \\
\hline $\begin{array}{l}\text { Montante } \\
\text { do Débito }\end{array}$ & 0,11 & 0,01 & 0,62 & 0,00 \\
\hline Alínea "b" & 10428,82 & 17111,51 & 0,04 & 0,54 \\
\hline Alínea "c" & 18783,83 & 15265,44 & 0,08 & 0,21 \\
\hline Alínea "d" & 47300,79 & 17685,56 & 0,15 & 0,01 \\
\hline $\begin{array}{l}\text { Mais de } \\
\text { um ato }\end{array}$ & 13708,21 & 15293,88 & 0,06 & 0,37 \\
\hline (Constant) & $-11259,04$ & 11311,38 & 0,37 \\
\hline $\begin{array}{l}\text { Montante } \\
\text { do Débito }\end{array}$ & 0,11 & 0,01 & 0,62 & 0,00 \\
\hline Alínea "c" & 8355,02 & 14040,19 & 0,04 & 0,55 \\
\hline Alínea "d" & 36871,98 & 16587,39 & 0,12 & 0,03 \\
\hline $\begin{array}{l}\text { Mais de } \\
\text { um ato }\end{array}$ & 3279,39 & 14011,75 & 0,01 & 0,82 \\
\hline Alínea "a" & $-10428,82$ & 17111,51 & $-0,03$ & 0,54 \\
\hline (Constant) & $-2903,79$ & 8552,02 & 0,32 \\
\hline $\begin{array}{l}\text { Montante } \\
\text { do Débito }\end{array}$ & 0,11 & 0,01 & 0,62 & 0,00 \\
\hline Alínea "d" & 28516,88 & 14705,23 & 0,09 & 0,05 \\
\hline $\begin{array}{l}\text { Mais de } \\
\text { um ato }\end{array}$ & $-5075,71$ & 11729,15 & $-0,02$ & 0,66 \\
\hline Alínea "a" & $-18783,86$ & 15244,05 & $-0,06$ & 0,22 \\
\hline Alínea "b" & $-8273,79$ & 13942,64 & $-0,03$ & 0,55 \\
\hline
\end{tabular}

Tabela 5 mostra os resultados dessa mesma análise para os dados da Amostra 2. As variáveis incluídas no modelo explicaram $29,6 \%\left(R_{2}=0,296\right)$ da variação no valor da multa do art. 57. Aumento no montante do débito esteve significantemente associado a aumento no valor da multa, porém com parâmetro menor que para a outra amostra (R\$0,01 para $R \$ 1,00)$. Novamente, a multa aplicada para os casos de desfalque ou desvio (alínea "d") foi significantemente maior do que aquela aplicada para os outros atos. Além disso, a multa foi significantemente menor para os casos de gestão ilegítima (alínea "b") do que para casos de ato 
de gestão ilegítimo que causou dano ao erário (alínea "c") e casos que envolveram mais de um ato.

Tabela 5. Parâmetros da regressão linear da multa do art. 57 em função do montante do débito e do tipo de conduta sancionada para a Amostra 2.

\begin{tabular}{|c|c|c|c|c|}
\hline Amostra 1 & B & Std. Erro & Beta & Sig. \\
\hline (Constant) & 14351,35 & 2162,39 & & 0,0 \\
\hline $\begin{array}{l}\text { Montante } \\
\text { do Débito }\end{array}$ & 0,01 & 0,01 & 0,39 & 0,00 \\
\hline Alínea "a" & $-6045,69$ & 4215,58 & $-0,07$ & 0,15 \\
\hline Alínea "b" & $-13641,44$ & 3476,99 & $-0,19$ & 0,00 \\
\hline Alínea "c" & $-4502,45$ & 3243,25 & $-0,07$ & 0,17 \\
\hline Alínea "d" & 20678,36 & 4515,12 & 0,22 & 0,00 \\
\hline (Constant) & 8346,93 & 3541,96 & & 0,02 \\
\hline $\begin{array}{l}\text { Montante } \\
\text { do Débito }\end{array}$ & 0,01 & 0,01 & 0,39 & 0,00 \\
\hline Alínea "b" & $-7636,68$ & 4470,09 & $-0,11$ & 0,09 \\
\hline Alínea "c" & 1502,72 & 4294,33 & 0,02 & 0,73 \\
\hline Alínea "d" & 26684,72 & 5328,38 & 0,29 & 0,00 \\
\hline $\begin{array}{l}\text { Mais de } \\
\text { um ato }\end{array}$ & 6092,81 & 4153,26 & 0,10 & 0,14 \\
\hline (Constant) & 934,13 & 2698,56 & & 0,73 \\
\hline $\begin{array}{l}\text { Montante } \\
\text { do Débito }\end{array}$ & 0,01 & 0,01 & 0,39 & 0,00 \\
\hline Alínea "c" & 8916,11 & 3628,16 & 0,14 & 0,01 \\
\hline Alínea "d" & 34099,01 & 4805,38 & 0,37 & 0,00 \\
\hline $\begin{array}{l}\text { Mais de } \\
\text { um ato }\end{array}$ & 13505,97 & 3460,95 & 0,23 & 0,00 \\
\hline Alínea "a" & 7372,02 & 4516,25 & 0,08 & 0,10 \\
\hline $\begin{array}{l}\text { (Cons- } \\
\text { tant) }\end{array}$ & 9836,06 & 2419,28 & & 0,00 \\
\hline $\begin{array}{l}\text { Montante } \\
\text { do Débito }\end{array}$ & 0,01 & 0,01 & 0,39 & 0,00 \\
\hline Alínea "d" & 25195,02 & 4619,45 & 0,27 & 0,00 \\
\hline $\begin{array}{l}\text { Mais de } \\
\text { um ato }\end{array}$ & 4603,55 & 3235,90 & 0,08 & 0,16 \\
\hline Alínea "a" & $-1530,21$ & 4348,89 & $-0,02$ & 0,73 \\
\hline Alínea "b" & $-9125,91$ & 3636,71 & $-0,13$ & 0,01 \\
\hline
\end{tabular}

As regressões que consideraram a porcentagem da multa do art. 57 em função das variáveis independentes indicaram, para as duas amostras, que aumentos no valor do débito estiveram significativa e inversamente relacionados a diminuições na porcentagem da multa, ou seja, quanto maior foi o montante do débito menor tendeu a ser a porcentagem da multa do art. 57. Na última etapa, as variáveis independen- tes explicaram 9,30\% $(R 2=0,093)$ e 49,0\% $(R 2=0,490)$ para as Amostras 1 e 2, respectivamente. Os parâmetros da regressão indicam que um aumento de $\mathrm{R} \$$ 1,00 no valor do montante do débito esteve associado a uma diminuição, estatisticamente significante, de $4,08 \%$ e 1,86\% no valor da multa para as Amostras 1 e 2, respectivamente. Além disso, para a Amostra 1, as porcentagens da multa foram significantemente maiores para a conduta de desfalque ou desvio de recursos do que para as outras condutas ou combinações de condutas, resultado que não foi corroborado para a Amostra 2.

As regressões que calcularam o valor da multa do art. 58 em função das variáveis independentes não mostraram efeito significante de nenhuma das variáveis, para nenhuma das duas amostras.

\section{Discussão}

O objetivo do presente trabalho foi examinar algumas características das contingências punitivas vigentes nos nós finais da cadeia que compõem a rede comportamental jurídica que tem como função reduzir a probabilidade de comportamentos de uso inadequado de recursos federais. Com a atribuição de julgar a prestação de contas de recursos federais e aplicar as sanções cabíveis em caso de irregularidades, o Tribunal de Contas da União atua no final da cadeia de uma rede composta pelos órgãos federais responsáveis pelos recursos, a CGU, o Ministério Público junto ao TCU, dentre outros. As análises se basearam em dados extraídos de uma lista pública que continha informações sobre os processos relativos às pessoas que tiveram suas contas julgadas irregulares, e foram divididas em uma parte descritiva das informações e outra parte inferencial que examinou variáveis que poderiam predizer os valores das sanções aplicadas.

As análises descritivas indicaram que mais de 90\% dos processos de TCE não são instauradas pelo TCU, mas, sim, por outros partícipes da rede comportamental jurídica, como os Ministérios e a CGU. Esse achado reflete o que indica o texto da lei, de acordo com o qual a autoridade administrativa competente, responsável pelos recursos deve instaurar a tomada de contas especial para apuração dos fatos, identificando os responsáveis e quantificando o dano, pois, 
se não o fizer, pode responder no processo com responsabilidade solidária (art. $8^{\circ}$ da Lei $8.443 / 92$ ). Os dados indicaram ainda que em mais de $70 \%$ dos casos há ocorrência de débito solidário nos processos analisados. Esse grande volume de processos com débito solidário pode advir da quantidade de pessoas que normalmente estão envolvidas nos contratos e convênios, o que é consistente com o fato de $60 \%$ das TCE terem envolvido convênios, nas amostras analisadas. Os convênios são firmados quando ocorre transferência de recursos financeiros da União aos entes subnacionais destinados à execução de programas de governo em regime de mútua cooperação. De um lado, o órgão da administração pública federal direta e, do outro, órgão ou entidade da administração pública estadual, distrital ou municipal. Compatível com essa interpretação, as análises descritivas também revelaram que, dentre os cargos (ou funções) ocupados pelas pessoas que tiveram suas contas julgadas como irregulares pelo TCU, a maior incidência ocorreu nos casos de prefeitos e secretários, mais de $46 \%$, seguido por presidente e diretor, mais de $17 \%$, e outros cargos, acima de $18 \%$. Tomados em conjunto, as informações sugerem, de forma quantitativa e sistêmica, que há maiores fragilidades e riscos nos casos em que os recursos são descentralizados para outros entes da federação, conforme já amplamente constatado em fiscalizações específicas do TCU.

Outra informação extraída das análises descritivas concerne à duração média dos processos de tomada de contas especiais no TCU, média que foi próxima de quatro anos, nas duas amostras examinadas. Essa média é menor do os prazos dos processos judiciais, tendo em vista que, recentemente, a Ministra Laurita Vaz, do Superior Tribunal de Justiça (STJ), durante o $9^{\circ}$ Encontro Nacional do Poder Judiciário,afirmou que a justiça deseja colocar como meta o compromisso de concluir em quatro anos o julgamento de processos em cada uma das instâncias da Justiça Federal (CNJ, 2015). Estreitamente relacionado à duração média, os dados analisados indicaram a ocorrência média de 0,5 recurso por TCE e que mais de $78 \%$ dos processos não envolveram qualquer recurso.

Quanto às análises preditivas, os resultados indicaram uma relação significativa e positiva entre o montante do débito e a multa do art. 57, ou seja, quanto maior o débito, maior tendeu a ser a multa aplicada. A tendência foi constatada nas duas amostras. A Lei 8.443 no art. 57 prevê que o Tribunal pode aplicar uma multa de até cem por cento do valor atualizado do dano causado ao erário, texto que, juntamente com o que indica a Constituição Federal, em seu art. 71 , inciso VIII ${ }^{4}$, pode desempenhar uma função discriminativa de indicar que comportamentos que geram maiores danos devem ser punidos com multas maiores. A aplicação de maiores penas para comportamentos mais gravosos parece ser uma prática comum nos sistemas jurídicos, como ilustrado pelo Código Penal. Portanto, se essa interpretação estiver correta, os dados mostram uma relação positiva entre multa e débito conforme previsto na lei. Relacionado a esse achado, cabe mencionar que, apesar da lei autorizar a aplicação de multa até $100 \%$ do valor do débito, nos dados analisados, a média da porcentagem da multa do art. 57 foi de $16 \%$ do valor do débito, nasduas amostras.

No que concerne à porcentagem da multa do art. 57, calculada em relação ao valor do débito, as análises de regressão indicaram uma relação significativa e negativa, ou seja, maiores valores de débito estiveram significativamente relacionados a menores porcentagens de multa, nas duas amostras (aumentos de R\$ 1,00 no débito estiveram associados a uma redução de $2 \%$ a $4 \%$ no valor da multa). Apesar desse achado ser surpreendente, a presente pesquisa não obteve informações (e.g., entrevista com magistrados, multas aplicadas a pessoas jurídicas) que pudessem servir de base para uma interpretação fundamentada. Quando comparado a outros subsistemas jurídicos do país, como por exemplo o sistema tributário, esse resultado difere da típica alíquota progressiva aplicada para alguns impostos, como o imposto de renda para pessoa física, de acordo com a qual a porcentagem de imposto aumenta para contribuintes com rendas mais altas. A comparação entre os dois con-

4 Art. 71 . O controle externo, a cargo do Congresso Nacional, será exercido com o auxílio do Tribunal de Contas da União, ao qual compete:

(..)

VIII - aplicar aos responsáveis, em caso de ilegalidade de despesa ou irregularidade de contas, as sanções previstas em lei, que estabelecerá, entre outras cominações, multa proporcional ao dano causado ao erário; 
juntos de contingências com finalidades tão diversas pode não se mostrar muito útil, mas talvez sirva para chamar a atenção para um fenômeno que requer explicação e para encorajar a procura por subsistemas mais facilmente comparáveis.

$\mathrm{O}$ art. 268 do Regimento Interno do TCU (vigente à época) complementa o art. 58 da Lei 8443/92, ao prever multa entre $5 \%$ a $95 \%$ do valor pré-estabelecido pelo TCU (valores atualizados anualmente) para as contas julgadas irregulares, nas quais não haja débito. Nos dados analisados, a média da porcentagem da multa relacionada ao art. 268 e art. 58 foi de $14 \%$ do valor máximo, nas duas amostras.

Como mencionado anteriormente, o texto legal (art. 16, inciso III, alíneasa, b, c e d, da Lei 8.443/92) cita quatro tipos de comportamentos ilícitos que podem justificar que as contas sejam julgadas irregulares. 0 comportamento que ocorreu com mais frequência foi dano ao erário decorrente de ato de gestão ilegítimo ao antieconômico (alínea "c"), representando mais de $25 \%$ dos casos, nas duas amostras. O segundo mais frequente foi prática de ato de gestão ilegal, ilegítimo, antieconômico, ou infração à norma legal ou regulamentar de natureza contábil, financeira, orçamentária, operacional ou patrimonial (alínea "b") que representoumais de $16 \%$ dos casos nas amostras. A combinação entre as alíneas "b" e "c" apareceu em terceiro, com mais de $14 \%$ nas amostras.

Na regressão linear da multa do art. 57 em função dos preditores, o ilícito desvio e desfalque de dinheiros, bens ou valores públicos (alínea "d") predisse multas maiores do que as multas aplicadas aos outros comportamentos (alínea "a", "b", "c" e mais de um ato), resultado observado nas duas amostras. Esses resultados parecem indicar que atos relacionados a desfalque ou desvio são considerado pelos Ministros como mais gravosos que os outros ilícitos, ou seja, a propensão a punir dos magistrados parece ser maior para tais casos (cf. Aguiar, 2017). Essa interpretação foi corroborada pela constatação de que $80 \%$ dos casos de aplicação da sanção prevista no art. 60 (i.e., inabilitação), sanção considerada mais severa (que depende do ato ser considerado grave e de decisão pelo Plenário), ocorreram com relação a desfalque ou desvio. Essa maior propensão a punir pode ser função do maior grau de adversividade gerado, nas sociedades modernas, por comportamentos ilícitos dolosos, como pode ser ilustrado pela existência de previsão de maiores penas para crimes dolosos, quando comparado a crimes culposos, na maioria das leis penais.

De forma geral, os presentes resultados sugerem que o arcabouço da análise comportamental do direito tem grande potencial para fundamentar o crescente interesse por pesquisas empíricas em direito. 0 modelo suscita, por exemplo, questões a respeito das propensões a punir e a delinquir, do sistema e da sociedade, cujas respostas podem fornecer relevantes subsídios para revisão e aprimoramento de contingências punitivas existentes, criação de novas contingências, identificação dos elementos funcionais que compõem as redes comportamentais jurídicas, avaliação da eficiência dos principais nós das redes, dentre muitos outros.

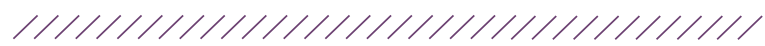




\section{Referências}

Aguiar, J. C. (2012). Legal contingencies: towards a radical behaviorist approach to law as a social system (Doctoral thesis, University of Aberdeen, Scotland, United Kingdom). Retrieved from http://digitool.abdn.ac.uk/webclient/StreamGate?folder id=0\&dvs=1497471365748 934

Aguiar, J. C. (2013). O direito como sistema de contingências sociais. Revista da Faculdade de Direito da Universidade Federal de Goiás, vol. 37, n. 2 , pp. 164-196.

Aguiar, J. C. (2014). Análise comportamental do direito: uma abordagem do direito como ciência do comportamento humano aplicada. Nomos, vol. 34, n. 2 , pp. 245-273.

Aguiar, J. C. (2015). Passos para uma abordagem evolucionária do direito. Revista da Faculdade de Direito da Universidade Federal do Paraná, vol. 60, n.1 , pp. 9-38.

Aguiar, J. C. (2016). Análise comportamental do direito: ideias básicas. In: B. M. Tabak, \& J. C. Aguiar, Direito, Economia e Comportamento Humano (pp. 15-26). Curitiba: CRV.

Aguiar, J. C. (2017). Teoria analítico-comportamental do direito. Porto Alegre: Núria Fabris.

Aguiar, J. C., \& Gobbo, L. O. (2016). Behavior analysis of law: a brief overview of the juxtaposition of law and radical behaviorism. In: J. C. Todorov, Trends in behavior analysis (pp. 81-103). Brasília: Technopolitik.

Catania, A. C. (1999). Aprendizagem: comportamento, linguagem e cognição ( $\left.4^{\mathrm{a}} \mathrm{ed}\right)$. Porto Alegre: Artmed. (Trabalho original publicado em 1998). CNJ (2015). Justiça Federal quer processos julgados em quatro anos em cada instância. Disponível em: http://www.cnj.jus.br/noticias/cnj/81014-justica-federal-quer-processos-julgados-em-quatro-anos-em-cada-instancia

Eisenberg, T., Rachlinski, J. J., Schwab, S. J., \& Wells, M. T. (2004). Editors' Introduction.Journal of Empirical Legal Studies, 1(1), v-vi.

Epstein, L., Landes, W. L., \& Posner, R. A. (2012). The Behavior of Federal Judges: A Theoretical and Empirical Study of Rational Choice. Cambridge, MA:Harvard University Press.

Hart, H. L. (1994). The Concept of Law. Oxford: Claredon.

Harzem, P., \& Miles, T. R. (1978). Conceptual issues in operant psychology. New York: John Wiley\& Sons.
Kelsen, H. (1998). Teoria Pura do Direito (J. B. Machado, Trans.). São Paulo:

Martins Fontes. (Original work, Reine Rechtslehre, published in 1960).

Lima, R. K. (2008). Por uma Antropologia do Direito no Brasil. Ensaios de Antropologia e de Direito: acesso à justiça e processos institucionais de administração de conflitos e produção da verdade jurídica em uma perspectiva comparada. Rio de Janeiro: Lumens Juris, pp. 01-38.

Lima, R. K., Varella, A. (2008). Saber Jurídico e Direito à Diferença no Brasil: questões de teoria e método em uma perspectiva comparada. Ensaios de Antropologia e de Direito: acesso à justiça e processos institucionais de administração de conflitos e produção da verdade jurídica em uma perspectiva comparada. Rio de Janeiro: Lumens Juris, pp. 89126.

Luhmann, N., Bednarz, J. J., \& Baecker, D. (1995). Social systems. Stanford, CA: Stanford University Press.

Machado-Neto, A. L. (1987). Sociologia Jurídica $\left(6^{a}\right.$ ed.) São Paulo. Saraiva

Nunes, M G. (2012). Jurimetria aplicada ao direito societário: Um estudo estatístico da dissolução de sociedade no Brasil. Tese de Doutorado em Direito Comercial. São Paulo: PUC-SP.

Oliveira-Castro, J. M., Coelho, D. S., \& Oliveira-Castro, G. A. (1999). Decrease of precurrent behavior as training increases: Effects of task complexity. The Psychological Record, 49, 299-325.

Polson, D. A., \& Parsons, J. A. (1994). Precurrent contingencies: Behavior reinforced by altering reinforcement probability for other behavior. Journal of the Experimental Analysis of Behavior, 61,427439.

Posner, R. A. (2007). Economic Analysis of Law ( $7^{\mathrm{a}} \mathrm{ed}$.). New York: Aspen Publishers.

Schauer, F. (2015). The Force of Law. Cambridge, MA: Harvard University Press.

Scuro-Neto, P. (2009). Sociologia Geral e Jurídica (6 ${ }^{a}$ ed.). São Paulo: Saraiva.

Skinner, B. F. (1953). Science and human behavior. New York: Free Press.

Skinner, B. F. (1957). Verbal behavior. Englewood Cliffs, NJ: Prentice-Hall.

Skinner, B. F. (1968). The technology of teaching. New York: Appleton-Century-Crofts. 
Skinner, B. F. (1969). Contingencies of reinforcement: a theoretical analysis. New York: Appleton-Century-Crofts.

Todorov, J. C. (2004). Da Aplysia à Constituição: evolução dos conceitos na análise do comportamento. Psicologia: Reflexão e Crítica, vol. 17, n. 2, pp. 151-156.

Todorov, J. C. (2005). Laws and the complex control of behavior. Behavior and social issues, vol. 14, pp. 86-91.

Zabala, F. J.; Silveira, F. F. (2014). Jurimetria: estatística aplicada ao direito. Revista Direito e Liberdade, Natal, v. 16, n. 1, p. 87-103, jan./abr. Quadrimestral. Disponível em: http://www.esmarn.tjrn.jus. br/revistas/index.php/revista_direito_e_liberdade/article/view/732/ 596.

Data de submissão/Submission date: 03.07.2017.

Data de aceitação para publicação/Acceptance date: 03.07.2018. 